\title{
Peruvian Agricultural Research
}

\author{
ISSNe 2706-9397
}

Homepage: http://revistas.unjfsc.edu.pe/index.php/PeruvianAgriculturalResearch CUniversidad Nacional José Faustino Sánchez Carrión, Lima, Perú

\section{Desarrollo de un Jardín Botánico en Soná, Panamá}

\author{
Development of a Botanical Garden in Sona, Panama
}

\section{J. Fernández ${ }^{1}$, R. D. Collantes $^{2} \mathbb{D}$, R. Atencio ${ }^{2 *} \mathbb{D}$}

https://doi.org/10.51431/par.v3i2.706

\section{Resumen}

Objetivos: Identificar los elementos para establecer el potencial desarrollo de un jardín botánico en la Finca FZ ubicada en Soná, Veraguas, Panamá. Metodología: Diversas especies de plantas frutales y maderables han sido establecidas dentro de la finca desde el año 2015. Durante el período de estudio, desarrollado desde el mes de julio hasta septiembre de 2021, se realizó un inventario de las especies de frutales (65) y maderables (34), presentes en la finca y la compilación de bibliografía, identificando los beneficios más importantes de cada especie. Resultados: El incremento de la diversidad de especies de plantas dentro de la colección actual, aunado a una serie de adecuaciones estructurales y alianzas estratégicas, permitirían establecer un jardín botánico de referencia nacional y regional. Considerando además que las especies de plantas establecidas tienen importancia desde el punto de vista agrícola, forestal y ecológico en la región, esto sería un aporte significativo en materia de educación ambiental e investigación científica. Conclusiones: la Finca FZ tiene potencial para convertirse en un jardín botánico con múltiples aplicaciones tanto en educación como en investigación, innovación y desarrollo social

Palabras clave: Biodiversidad, frutales, jardín botánico, maderables

\begin{abstract}
Objectives: of this work was to identify the elements to establish the potential development of a botanical garden in the FZ Farm located in Soná, Veraguas, Panama. Methodology: Various species of fruit and timber plants have been established within the farm since 2015. During the study period, developed from July to September 2021, an inventory of fruit tree species (65) and timber (34), present on the farm was made and a bibliographical review, identifying the most important benefits of each species. Results: The increase in the diversity of plant species within the current collection, along with a series of structural improvements and strategic alliances, would allow the establishment of a botanical garden of national and regional reference. Considering also that the established plant species are important for agriculture, forestry, and ecology in the region, this would be a significant contribution in terms of environmental education and scientific research. Conclusions: FZ Farm has potential to become a botanical garden with multiple applications both in education and in research, innovation, and social development.
\end{abstract}

Keywords: Biodiversity, fruit trees, botanical garden, timber trees

\footnotetext{
${ }^{1}$ Finca FZ, El Barrero de El Marañón, Soná, Veraguas, Panamá.

${ }^{2}$ Instituto de Innovación Agropecuaria de Panamá.

*Autor para correspondencia: randy.atencio@gmail.com
} 


\section{Introducción}

La deforestación en Panamá a partir del año 1947 ha sido acelerada, reduciendo a menos del $45 \%$ la superficie boscosa del territorio nacional (Imbach et al., 2016). Además, los suelos fértiles que perdieron cobertura vegetal por malas prácticas agropecuarias han sufrido los impactos de la erosión en sus diversas variantes (por lluvia, viento, masa, etc.), empobreciendo los suelos de manera dramática, principalmente en las regiones rurales (Ruiz, 2019). A esto se suma la tasa de pobreza en dichas regiones, la cual alcanza hasta el 30,9\% de la población (Pittí et al., 2019). La pérdida de la biodiversidad está asociada directamente con la deforestación, agricultura migratoria, erosión genética, sobre explotación, obras civiles, tráfico ilegal de especies, ingreso de especies exóticas, contaminación del agua; perdiéndose así hábitats naturales (Autoridad Nacional del Ambiente, 2010).

Con el cambio climático, se pronostican impactos directos en la producción de cultivos de seguridad alimentaria y los recursos naturales del país (Autoridad Nacional del Ambiente, 2010). Por otro lado, los planes de educación han integrado paulatinamente componentes ambientales y de sostenibilidad, con un enfoque agroambiental en los planes educativos en todos los niveles. Pero este cambio hacia el desarrollo sustentable requiere la incorporación de políticas agroambientales, que concilien la producción de alimentos, la seguridad alimentaria y la conservación del ambiente (Organización de las Naciones Unidas para la Alimentación y la Agricultura, 2015).

Los jardines botánicos constituyen un pilar fundamental para la educación ambiental; considerando que las personas entran en contacto con un campo de acción dinámico, iniciativas y acciones en permanente vitalidad (Martínez et al., 2012). Además, los jardines botánicos poseen diversas funciones, por lo cual no pueden limitarse a una sola clasificación; presentándose de allí la definición potencial de jardines botánicos, como las instituciones que mantienen colecciones documentadas de plantas vivas con propósitos de investigación científica, conservación, exhibición, cultura, educación y desarrollo sustentable, aunque en diferentes 88 combinaciones y énfasis (Forero, 1989; Wyse \& Sutherland, 2000; Vovides \& Hernández, 2006).

Sumado a todo lo anterior, los jardines botánicos tienen un importante papel en la producción de semillas, dispersión, polinización y fenología de diversas especies de plantas de importancia nacional y regional. Considerando el programa de actividades que ofrecen, pueden dirigirse a un público general y diverso en edad, género, nivel de instrucción e interés de estudio; siendo frecuente el uso de publicaciones en periódico, panfletos, guías y catálogos (Forero, 1989).

Para obtener el estatus de jardín botánico, además de cumplir una función recreativa, educativa o poseer una colección diversa; requieren también estar involucrados dentro de una actividad científica (Vovides \& Hernández, 2006). Por tanto, no deben confundirse con un jardín particular o un centro experimental, reserva o parque ecológico o urbano (Vovides \& Hernández, 2006).

Igualmente, losjardines botánicos contribuyen al sector agropecuario en la búsqueda de nuevos modelos productivos, en la diversificación, la biodiversidad del paisaje con la incorporación de frutales, maderables y hortalizas de manera sostenible dentro de fincas integradas con un mayor rendimiento y eficiencia biológica, creando mejores condiciones de uso del suelo, aprovechando espacios para sembrar diversos cultivos, donde el enfoque agroecológico y las ventajas biológicas de los policultivos prevalece para el manejo agroecológico de los insectos dañinos (Salazar-Díaz, 2015).

En este aspecto, la Finca FZ se ha constituido inicialmente en un proyecto piloto y modelo de escuela de campo en las provincias centrales, enfocada en el tema agroforestal. Se pretende lograr el establecimiento de alianzas estratégicas con el Instituto Smithsonian de Investigaciones Tropicales, la Facultad de Ciencias Naturales, Exactas y Tecnología y la Facultad de Ciencias Agropecuarias de la Universidad de Panamá. Todo ello, para compartir información de especies nativas y exóticas en Panamá (Ministerio del Ambiente, 2021). Por lo expuesto, el objetivo del presente trabajo fue realizar el inventario

Peruvian Agricultural Research 3(2), 87-103, 2021 
inicial de las especies frutales y maderables establecidas destacando sus beneficios básicos para que la Finca FZ pueda transformarse en un Jardín Botánico.

\section{Metodología}

El área de estudio corresponde a la Finca FZ, ubicada en la comunidad de El Barrero, Corregimiento de El Marañón, Distrito de Soná, Veraguas-Panamá $\left(8^{\circ} 0^{\prime} 15.79^{\prime \prime} \mathrm{N} 82^{\circ} 16^{\prime} 29.92^{\prime \prime}\right.$ O). La finca fue establecida en el año 2015, como emprendimiento de la familia FernándezZurita, incluyendo un total de 17,3 hectáreas. La investigación, de carácter exploratorio y prospectivo, se desarrolló desde el mes julio hasta octubre de 2021. Se realizó un inventario de las especies de frutales y maderables establecidas en la finca y se compiló información bibliográfica, sobre los principales beneficios de los frutales y maderables de las especies inventariadas, con el fin de justificar y promover el establecimiento de estas dentro de un modelo de finca orientado a transformarse en jardín botánico de referencia regional y nacional.

\section{Resultados y discusión}

De acuerdo con los resultados (Tabla 1), se encontró un total de 65 especies frutales, distribuidas en 30 familias; de las cuales la mayor cantidad de especies pertenecen a las familias Myrtaceae (con 9,23\% [6 especies]), Rutaceae (con 7,69\% [5 especies]), Anacardiceae (con 7,69\% [5 especies]) y Arecaceae (con 7,69\% [5 especies]), incluyendo dentro las mismas frutas consideradas tradicionales como el mango y exóticas como el mangotin, que juegan un papel primordial dentro de la seguridad alimentaria y complemento nutricional de una gran parte de la población panameña, además de tener usos medicinales en determinados casos. Los frutales constituyen una fuente nutricional de antioxidantes, vitaminas, minerales, carbohidratos, fibra, entre otros, con una estrecha relación con la salud humana. Esto se ha convertido en un área de estudio en constante crecimiento, por su importancia como componentes bioactivos y actividades biológicas aplicables en el área médica, farmacéutica, alimentaria y ambiental (de la Rosa-Hernández et al., 2016). Diversas frutas, como por ejemplo el rambután o mamón chino (Nephelium lappaceum L.), pueden integrarse dentro de un sistema de producción de policultivos y la utilización de coberturas como alternativas agroecológicas, dando un énfasis en el proceso de incrementar la biodiversidad de los agroecosistemas con aportes socioeconómicos tangibles y como contribución alterna a los monocultivos (Osorio-Espinoza et al., 2019).

Tabla 1

Lista de especies de frutales encontrados en la Finca FZ

\begin{tabular}{|c|c|c|c|c|}
\hline Familia & Nombre Científico & $\begin{array}{l}\text { Nombre } \\
\text { común }\end{array}$ & Utilización y Beneficio & $\begin{array}{c}\text { Referencias } \\
\text { literarias }\end{array}$ \\
\hline Anacardiaceae & Spondias mombin L. & Jobo & $\begin{array}{l}\text { Los frutos maduros son dulces y a la vez } \\
\text { ácidos utilizados en la preparación de } \\
\text { refrescos, vinos y helados artesanales. } \\
\text { La madera se utiliza en la fabricación de } \\
\text { cajas, plywood y pulpa para papel. }\end{array}$ & Chizmar, 2009 \\
\hline Anacardiaceae & $\begin{array}{l}\text { Anacardium } \\
\text { occidentale L. }\end{array}$ & $\begin{array}{l}\text { Marañón } \\
\text { Pepita }\end{array}$ & $\begin{array}{l}\text { El pseudo fruto o manzana es rico } \\
\text { en Vitamina C con propiedades } \\
\text { antiescorbúticas además de diversas } \\
\text { propiedades medicinales, utilizado } \\
\text { para la elaboración de jugos, dulces } \\
\text { y jaleas. La nuez se puede consumir } \\
\text { asada, tostada, salada o dulce y puede } \\
\text { ser destinada a diversos fines culinarios. }\end{array}$ & $\begin{array}{l}\text { Autoridad del Canal } \\
\text { de Panamá, } 2009\end{array}$ \\
\hline Anacardiaceae & Mangifera indica L. & Mango & $\begin{array}{l}\text { Fruto rico en Vitamina A y C, así como } \\
\text { ácido fólico, fibra, Potasio, fitoquímicos } \\
\text { y beta-carotenos; se utiliza maduro } \\
\text { y verde, pudiendo ser utilizado para } \\
\text { preparar jugos, ensaladas, salsas, } \\
\text { mermeladas, sorbetes y postres. }\end{array}$ & $\begin{array}{l}\text { Instituto de Nutrición } \\
\text { de Centro América y } \\
\text { Panamá - Secretaría } \\
\text { Ejecutiva del Consejo } \\
\text { Agropecuario } \\
\text { Centroamericano, } 2017\end{array}$ \\
\hline
\end{tabular}


$\begin{array}{rll}\text { Anacardiaceae Spondias purpurea L. } & \text { Ciruela } \\ & \text { Traqueadora }\end{array}$

$\begin{array}{ll}\text { Anacardiaceae } & \begin{array}{l}\text { Spondias dulcis } \\ \text { Parkinson }\end{array}\end{array}$ Mangotín

Annonaceae Annona muricata L.

Annonaceae Annona cherimolla Chirimoya Mill.

Arecaceae Cocos nucifera L. Coco

$\begin{array}{ll}\text { Arecaceae } & \begin{array}{l}\text { Bactris gasipaes } \\ \text { Kunth }\end{array}\end{array}$

Arecaceae

Bactris major Jacq.

Palma

Brava

Morada,

Uvito

Arecaceae

Arecaceae

Attalea rostrata

Oerst.

Acrocomia aculeata

(Jacq.) Lodd. ex

Mart.

Palma de

Corozo

Palma Rea

Bignoniaceae Crescentia cujete L. Calabaza
La pulpa de los frutos se come cruda o cocida. Los frutos maduros se usan para elaborar jugos, vinos y licores. El follaje se emplea como forraje para el ganado.

Los frutos son comestibles. La pulpa de los frutos verdes se utiliza para preparar una ensalada a la cual se le agrega sal y pimienta al gusto.

La pulpa de los frutos maduros es comestible y se utiliza para preparar jugos, batidos y helados. Las hojas se utilizan para preparar té medicinal, empleado para combatir malestares estomacales y la diarrea.

Fruta altamente nutritiva, rica en carbohidratos $\mathrm{y}$ tiene alto valor energético. Alto contenido de minerales, hierro, calcio, fósforo, agua, fibras, cenizas y varias vitaminas (B1, B2 y B3). La fruta se usa en la elaboración de helados, vinos, batidos de leche o sorbetes y también se procesa en forma de helado, yogur, flan, jugos y vinos. Las semillas presentan propiedades farmacológicas.

Rica en diversos minerales, pulpa rica Instituto de Nutrición en fibra y grasas saturadas; se utiliza el de Centro América y agua fresca, la pulpa cruda o rallada para Panamá - Secretaría preparar leche de coco, bebidas, postres, Ejecutiva del Consejo helados, entre otros fines.

Centroamericano, 2017

Autoridad del Canal

con sal. Una vez cocido se utiliz la preparación de diversas comidas como ensaladas, ceviches, encurtidos, compotas y jaleas. Puede procesarse para obtener harina de uso en panadería, pastelería y fabricación de fideos. El palmito es un producto gourmet.

Los frutos se consumen maduros, solos o en chicas. Los frutos se pueden utilizar para preparar licores. El cogollo o meristemo de las hojas tiernas, puede ser consumido crudo o cocinado, frito o asado.

Los frutos se pueden cocinar. La savia que emana del tronco cortado se recoge para elaborar una deliciosa bebida conocida en Panamá como vino de palma.

Los frutos contienen aceite utilizado para el consumo humano, también se emplean para fabricar un tipo de licor. Las hojas se utilizan para la fabricación de techos en casas y ranchos de comunidades rurales y áreas urbanas.

El fruto se emplea para fabricar totumas e instrumentos musicales como las güiras o churucas. La pulpa del fruto se utiliza para curar enfermedades cutáneas y la erisipela, también es purgativa y expectorante, pero cuando está madura sirve como abortivo para el ganado.
Agropecuario

de Panamá, 2009

Perez \& Condit

Pérez \& Condit,

Pérez \& Condit, 2021.

Pérez \& Condit, 2021.

Chizmar, 2009

Pérez \& Condit, 2021.

Pérez \& Condit, 2021.

Pérez \& Condit, 2021. 
Bignoniaceae Crescentia cujete L. Calabaza

Bixaceae Bixa orellana L. Achiote

\section{Bromeliaceae Bromelia pinguin L. Piro}

$\begin{array}{lll}\text { Cactaceae } & \begin{array}{l}\text { Acanthocereus } \\ \text { tetragonus (L.) }\end{array} & \text { Pitahaya } \\ & \text { Hummelinck } & \\ \text { Caricaceae } & \text { Carica papaya L. } & \text { Papaya }\end{array}$

Chrysobalanaceae

Chrysobalanaceae

Licania platypus
(Hemsl.) Fritsch

Chrysobalanus icaco Icaco

$\mathrm{L}$.

Zapote de Monte
El fruto se emplea para fabricar totumas e instrumentos musicales como las güiras o churucas. La pulpa del fruto se utiliza para curar enfermedades cutáneas y la erisipela, también es purgativa y expectorante, pero cuando está madura sirve como abortivo para el ganado.

Es rico en vitamina $\mathrm{C}$ y utilizado en la alimentación, medicamentos $\mathrm{y}$ cosmetología. Se utiliza como la materia colorante extraída de la cubierta de las semillas frescas (bixina) para dar color a comidas en general, así como en tintorería general. El árbol puede ser utilizado en sistemas agroforestales

Alto contenido de vitaminas C, B1, Instituto de Nutrición B6, ácido fólico, Magnesio, Hierro, de Centro América y flavonoides, carotenoides y complejo Panamá - Secretaría de enzimas; se utiliza fresca o preparada Ejecutiva del Consejo en jugos, jaleas, sorbetes, postres, Agropecuario ensaladas, salsas y aderezos.

Centroamericano, 2017

Los frutos se consumen crudos, en refrescos o almíbar y tiene un alto contenido de Vitamina $\mathrm{C}$ y Calcio. Las plantas se pueden utilizar de manera ornamental, para fibras para artesanías y como cerca viva.

La pulpa de los frutos maduros es comestible y se utiliza para fabricar refrescos. Los tallos se emplean en cercas vivas.

Utilizada fresca, batidos, ensaladas, jaleas, postres y dulces. Con altos contenidos de ácido fólico, Potasio, Papaína, Vitaminas A y C.

Chizmar, 2009

Chizmar, 2009;

Pérez \& Condit, 2021.

Instituto de Nutrición de Centro América y Panamá - Secretaría

Ejecutiva del Consejo Agropecuario

Centroamericano, 2017

\section{Clusiaceae \\ Garnicia intermedia (Pittier) Hammel}

Sastra, Satra

Clusiaceae Garcinia mangostana Mangostán L.
La pulpa de los frutos maduros crudos tiene un sabor dulce que se utilizan para preparar refrescos y bebidas fermentadas, así como jaleas y conservas. Se utiliza también para ornamentales y cercas vivas.

La pulpa de los frutos maduros crudos es comestible de sabor dulce y aromática, que pueden utilizarse para refrescos. La madera es empleada en construcciones rurales. El árbol se cultiva como frutal, ornamental y para sombra.

La pulpa blanca de sabor ácido y agradable al paladar que rodea las semillas se come cruda. El fruto tiene potencial como materia prima para la elaboración de jugos, jaleas y mermeladas.

Chizmar, 2009

Chizmar, 2009; Pérez \& Condit, 2021.

Chizmar, 2009; Pérez \& Condit, 2021.

El arilo blanco que rodea las semillas se come crudo, es de sabor dulce y agradable al paladar. La corteza y las Pérez \& Condit, 2021. 


\begin{tabular}{|c|c|c|c|c|}
\hline Fabaceae & $\begin{array}{l}\text { Inga spectabilis (DC.) } \\
\text { H.S. Irwin \& Barneby }\end{array}$ & Guaba & $\begin{array}{l}\text { Es una planta con registros como } \\
\text { antioxidante, diurético, vasodilatador e } \\
\text { inmunoestimulante. }\end{array}$ & Chizmar, 2009 \\
\hline Fabaceae & Tamarindus indica L. & Tamarindo & $\begin{array}{l}\text { Alto contenido de fibra, Potasio, } \\
\text { Fósforo, Magnesio y Hierro; Utilizada } \\
\text { en pulpa, bebidas, ensaladas, salsas, } \\
\text { postres, helados y dulces. }\end{array}$ & $\begin{array}{l}\text { Instituto de Nutrición } \\
\text { de Centro América y } \\
\text { Panamá - Secretaría } \\
\text { Ejecutiva del Consejo } \\
\text { Agropecuario } \\
\text { Centroamericano, } 2017\end{array}$ \\
\hline Fabaceae & $\begin{array}{l}\text { Inga laurina }(\mathrm{Sw} .) \\
\text { Willd. }\end{array}$ & $\begin{array}{l}\text { Guabita } \\
\text { Cansa Boca }\end{array}$ & $\begin{array}{l}\text { El arilo blanco que cubre las semillas } \\
\text { cuando los frutos están maduros es } \\
\text { comestible. Gran potencial como } \\
\text { planta melífera en fincas dedicadas a la } \\
\text { apicultura. }\end{array}$ & $\begin{array}{l}\text { Pérez \& Condit, } \\
2021 .\end{array}$ \\
\hline Flacourtiaceae & $\begin{array}{l}\text { Flacourtia jangomas } \\
\text { (Lour.) Raeusch. }\end{array}$ & $\begin{array}{l}\text { Uva } \\
\text { Tropical }\end{array}$ & $\begin{array}{l}\text { La pulpa verde amarillenta de los frutos } \\
\text { es utilizada principalmente para jaleas y } \\
\text { conservas, rara vez se come fresca, por } \\
\text { ser muy astringente. }\end{array}$ & León, 2000 \\
\hline Lauraceae & $\begin{array}{l}\text { Persea americana } \\
\text { Mill. }\end{array}$ & Aguacate & $\begin{array}{l}\text { Vitamina E, ácido fólico, grasas } \\
\text { monoinsaturadas, magnesio, Potasio } \\
\text { y alto valor energético; fruta utilizada } \\
\text { fresca o preparada en, ensaladas, } \\
\text { aderezos, salsas, postres, batidos y } \\
\text { helados, así como para diversos platos } \\
\text { culinarios. }\end{array}$ & $\begin{array}{l}\text { Instituto de Nutrición } \\
\text { de Centro América y } \\
\text { Panamá - Secretaría } \\
\text { Ejecutiva del Consejo } \\
\text { Agropecuario } \\
\text { Centroamericano, } 2017\end{array}$ \\
\hline Lecythidaceae & $\begin{array}{l}\text { Couroupita } \\
\text { nicaraguarencis DC. }\end{array}$ & $\begin{array}{l}\text { Fruta de } \\
\text { Mico-Bala }\end{array}$ & $\begin{array}{l}\text { Los frutos son cápsulas leñosas. Tiene } \\
\text { potencial para ser cultivada como } \\
\text { ornamental. }\end{array}$ & Grijalva, 2006 \\
\hline Lythraceae & Punica granatum L. & Granada & $\begin{array}{l}\text { Se consume como fruta fresca. } \\
\text { Es altamente nutritiva, rica en } \\
\text { carbohidratos, tiene alto valor energético } \\
\text { y contenido de minerales, hierro, calcio, } \\
\text { fósforo, agua, fibras y diversas vitaminas } \\
\text { (B1, B2 y B3). }\end{array}$ & Orellana, 2014 \\
\hline Malpighiaceae & $\begin{array}{l}\text { Byrsonima crassifolia } \\
\text { (L.) Kunth }\end{array}$ & Nance & $\begin{array}{l}\text { Los frutos tienen un sabor agridulce } \\
\text { y contienen Fósforo, Calcio, Hierro, } \\
\text { Vitaminas A, B y C. Tienen una alta } \\
\text { proporción de fibra y taninos y bajos } \\
\text { porcentaje de aceite; utilizada para } \\
\text { refrescos, jaleas, confites, dulces y } \\
\text { helados, además de la conocida Pesada } \\
\text { de Nance en Panamá. }\end{array}$ & Chizmar, 2009 \\
\hline Malpighiaceae & Malpighia glabra L. & Cereza & $\begin{array}{l}\text { Los frutos se consumen frescos y crudos } \\
\text { al natural. La pulpa tiene un ligero sabor } \\
\text { ácido y es rica en Vitamina C. }\end{array}$ & Chizmar, 2009 \\
\hline Malvaceae & $\begin{array}{l}\text { Matisia cordata } \\
\text { Humb. \& Bonpl. }\end{array}$ & $\begin{array}{l}\text { Zapote } \\
\text { amarillo }\end{array}$ & $\begin{array}{l}\text { Los frutos maduros son muy aromáticos } \\
\text { y tienen un sabor muy dulce, de los } \\
\text { cuales también se pueden extraer } \\
\text { jugos, mermeladas, postres, helados } \\
\text { y conservas. La madera se utiliza en } \\
\text { construcciones rurales, en carpintería, } \\
\text { para elaborar mangos de herramientas e } \\
\text { implementos agrícolas y como leña. }\end{array}$ & Chizmar, 2009 \\
\hline Malvaceae & Theobroma cacao L. & Cacao & $\begin{array}{l}\text { Las semillas se utilizan para la } \\
\text { producción de chocolate y la pulpa } \\
\text { blanca que rodea los frutos es comestible } \\
\text { como alimento energético. La semilla } \\
\text { contiene principios estimulantes tales } \\
\text { como teobromina y cafeína, almidón, } \\
\text { proteínas y fibras. La manteca de } \\
\text { cacao tiene propiedades emolientes } \\
\text { y cicatrizantes, utilizadas en la } \\
\text { preparación de productos farmacéuticos } \\
\text { y cosméticos. }\end{array}$ & $\begin{array}{l}\text { León, 2000; Pérez } \\
\text { \& Condit, } 2021\end{array}$ \\
\hline
\end{tabular}




\begin{tabular}{|c|c|c|c|c|}
\hline Malvaceae & $\begin{array}{l}\text { Hibiscus sabdariffa } \\
\text { L. }\end{array}$ & $\begin{array}{l}\text { Saril, } \\
\text { Rosella }\end{array}$ & $\begin{array}{l}\text { Es cultivada por sus cálices carnosos y } \\
\text { rojos, ricos en ácido maleico, con los } \\
\text { que se preparan refrescos calientes y } \\
\text { fríos, en jaleas y mermeladas, crudos o } \\
\text { cocinados, con algunas variedades para } \\
\text { obtener fibras. }\end{array}$ & León, 2000 \\
\hline Moraceae & $\begin{array}{l}\text { Artocarpus altilis } \\
\text { (Parkinson) Fosberg }\end{array}$ & Fruta de Pan & $\begin{array}{l}\text { La fruta madura se come en dulce o se } \\
\text { deja fermentar y se cocina al horno como } \\
\text { si fuera pan. Es un alimento energético, } \\
\text { ya que contiene almidón, hierro, calcio, } \\
\text { fósforo y Niacina. La savia lechosa es } \\
\text { empleada medicinalmente para curar } \\
\text { problemas de la piel. }\end{array}$ & $\begin{array}{l}\text { Pérez \& Condit, } \\
2021 .\end{array}$ \\
\hline Moraceae & $\begin{array}{l}\text { Artocarpus lacucha } \\
\text { Buch.-Ham. ex } \\
\text { D.Don }\end{array}$ & $\begin{array}{l}\text { Fruta de } \\
\text { Mono }\end{array}$ & $\begin{array}{l}\text { La planta tiene valiosas propiedades } \\
\text { farmacológicas. El fruto contiene } \\
\text { antioxidantes que incluyen flavonoides } \\
\text { y ácido fenólico. }\end{array}$ & Hossain et al., 2016 \\
\hline Moraceae & $\begin{array}{l}\text { Artocarpus } \\
\text { heterophyllus Lam. }\end{array}$ & Yaca & $\begin{array}{l}\text { La pulpa de la fruta se come cruda, } \\
\text { cocinada o en dulces, además que es } \\
\text { utilizada en la alimentación de ganado } \\
\text { vacuno. }\end{array}$ & León, 2000 \\
\hline Musaceae & Musa sapientum L. & Banano & $\begin{array}{l}\text { La fruta se utiliza fresca, en batidos, } \\
\text { compotas, helados, postres, entre otros, } \\
\text { con alto contenido de Vitamina A, rica } \\
\text { en carbohidratos, rica en fibra y Potasio. }\end{array}$ & $\begin{array}{l}\text { Instituto de Nutrición de } \\
\text { Centro América y Panamá } \\
\text { - Secretaría Ejecutiva del } \\
\text { Consejo Agropecuario } \\
\text { Centroamericano, } 2017\end{array}$ \\
\hline Musaceae & $\begin{array}{l}\text { Musa x paradisiaca } \\
\text { L. }\end{array}$ & Plátano & $\begin{array}{l}\text { Los frutos se consumen maduros y } \\
\text { verdes para diferentes platos culinarios y } \\
\text { procesamiento industrial. Es una rica fuente } \\
\text { de Potasio, Calcio, Nitrógeno, Fósforo, } \\
\text { Vitaminas y Almidón. Posee propiedades } \\
\text { astringentes, antifúngicas y antibióticas. }\end{array}$ & Blasco \& Gómez, 2014 \\
\hline Myrtaceae & $\begin{array}{l}\text { Syzygium malaccense } \\
\text { (L.) Merr. \& L.M. } \\
\text { Perry }\end{array}$ & $\begin{array}{l}\text { Marañón } \\
\text { Curazao }\end{array}$ & $\begin{array}{l}\text { El fruto que es una baya grande cuando } \\
\text { maduras con un color rojo brillante a } \\
\text { rosado y con una pulpa blanco y carnosa } \\
\text { que es comestible. La planta se utiliza } \\
\text { como planta ornamental en parques y } \\
\text { avenidas. Las raíces son efectivas contra } \\
\text { la disentería, diabetes, el estreñimiento y } \\
\text { como diurético. }\end{array}$ & $\begin{array}{l}\text { Autoridad del Canal } \\
\text { de Panamá, 2009; } \\
\text { Pérez \& Condit, } \\
2021\end{array}$ \\
\hline Myrtaceae & $\begin{array}{l}\text { Psidium guineense } \\
\text { Sw. }\end{array}$ & $\begin{array}{l}\text { Guayabita } \\
\text { Sabanera }\end{array}$ & $\begin{array}{l}\text { Los frutos maduros son comestibles } \\
\text { ricos en Vitamina C y agentes } \\
\text { antioxidantes, con los que se preparan } \\
\text { jugos, mermeladas y jaleas. La madera } \\
\text { es empleada para postes de cercas. }\end{array}$ & $\begin{array}{l}\text { Chizmar, 2009; } \\
\text { Pérez \& Condit, } \\
2021 .\end{array}$ \\
\hline Myrtaceae & $\begin{array}{l}\text { Zyzygium aqueum } \\
\text { (Burm. f.) Alston }\end{array}$ & $\begin{array}{l}\text { Manzana de } \\
\text { Agua }\end{array}$ & $\begin{array}{l}\text { Frutos de color rojo o blanco con } \\
\text { manchas rojizas de pulpa blanca con alto } \\
\text { contenido de Vitamina C. }\end{array}$ & $\begin{array}{l}\text { León, 2000; } \\
\text { Saptarini \& } \\
\text { Herawati, } 2017\end{array}$ \\
\hline Myrtaceae & $\begin{array}{l}\text { Psidium } \\
\text { friedrichsthalianum } \\
\text { (Berg) Nied. }\end{array}$ & Cas & $\begin{array}{l}\text { El fruto maduro es de color amarillo } \\
\text { con el epicarpio delgado y abundantes } \\
\text { semillas rodeadas de pulpa ácida con } \\
\text { la que se prepara refrescos. La madera } \\
\text { es empleada en construcciones pesadas, } \\
\text { puentes, pisos y postes de cercas. }\end{array}$ & $\begin{array}{l}\text { León, 2000; Pérez \& } \\
\text { Condit, 2021. }\end{array}$ \\
\hline Myrtaceae & $\begin{array}{l}\text { Syzygium jambos (L.) } \\
\text { Alston }\end{array}$ & Pomarosa & $\begin{array}{l}\text { Los frutos maduros son comestibles. La } \\
\text { pulpa es delgada y blanca, además de } \\
\text { dulce y aromática. }\end{array}$ & $\begin{array}{l}\text { León, 2000; Pérez \& } \\
\text { Condit, } 2021 .\end{array}$ \\
\hline Myrtaceae & $\begin{array}{l}\text { Psidium cattleianum } \\
\text { Afzel. ex Sabine }\end{array}$ & $\begin{array}{l}\text { Guayaba } \\
\text { china, } \\
\text { Guayaba } \\
\text { japonesa }\end{array}$ & $\begin{array}{l}\text { La pulpa delgada y blanca, dulce y } \\
\text { aromática, es de sabor superior a la } \\
\text { guayaba. }\end{array}$ & León, 2000 \\
\hline
\end{tabular}


Oxalidaceae

Averrhoa carambola

$\mathrm{L}$.

$\begin{array}{lll}\text { Passifloraceae } & \begin{array}{l}\text { Passiflora } \\ \text { quadrangularis L. }\end{array} & \text { Granadilla } \\ \text { Passifloraceae } & \begin{array}{l}\text { Passiflora seemannii } \\ \text { Griseb. }\end{array} & \text { Guate } \\ \text { Passifloraceae } & \begin{array}{l}\text { Passiflora edulis } \\ \text { Sims }\end{array} & \text { Maracuyá }\end{array}$

$\begin{array}{lll}\text { Phyllanthaceae } & \begin{array}{l}\text { Phyllantus acidus } \\ \text { (L.) Skeels }\end{array} & \text { Grosella } \\ \text { Rhamnaceae } & \begin{array}{l}\text { Ziziphus mauritiana } \\ \text { Lam. }\end{array} & \begin{array}{l}\text { Guinda, } \\ \text { Aprin }\end{array}\end{array}$

Rosaceae

Rubiaceae

Rubiaceae

Rubiaceae

Rutaceae
Coffea canephora L.

Alibertia edulis

(Rich.) A. Rich. ex

DC.

Rubus eriocarpus

Liebm.

Morinda citrifolia L. Noni

Citrus sinensis (L.) Naranja Osbeck robusta
Café, café
El fruto es comestible con un sabor agridulce, utilizado para preparar jugos, y se le atribuyen propiedades medicinales como febrífugo,

Cuando maduro el fruto, puede aportar a la alimentación carbohidratos, fibra cruda, Calcio y Vitamina A.

Los frutos se consumen frescos. La planta tiene un potencial como ornamental y frutal.

Las frutas se utilizan frescas procesadas Instituto de Nutrición en jugos o batidos, jaleas, sorbetes, de Centro América y postres, salsas y cócteles o ponches. Panamá-Secretaría Son ricas en Vitamina A, E y C, en fibra, Ejecutiva del Consejo Potasio, Magnesio, Hierro y fósforo, Agropecuario antocianinas, carotenoides y compuestos Centroamericano, 2017 organosulfurados.

Los frutos aplanados se comen León, 2000

cocinados, en conservas o dulces.

Del fruto se obtiene un mucílago rico en Vitamina C, A y B. Los frutos son recogidos antes de la madurez y se consumen secos, como dátiles, o se les prepara en jaleas y mermeladas.

Zarzamora Los frutos son de sabor agridulce, los cuales se consumen en fresco y se utilizan para elaborar jugos, néctares, mermeladas, jaleas, helados, dulces y adiciones para repostería. Sus frutos son ricos en Vitamina C, Calcio y fósforo, con carotenoides y antocianos que sirven como antioxidantes.

El fruto contiene Proxeronina, que es Autoridad del convertida por el organismo en Xeronina, que actúa como un regenerador celular, que acelera la curación de una serie de enfermedades como diabetes, cáncer, artritis, asma, problemas digestivos y de otras afecciones de salud.

A partir de los granos tostados y molidos se elabora la bebida de café, que contiene una sustancia estimulante conocida como cafeína. El café también es utilizado para la producción de fármacos, refrescos de cola, confitería, repostería aromatizante en helados y bombones, además de ser utilizado en sistemas agroforestales.

Zumbo

Los frutos maduros son comestibles y la pulpa es de sabor agradable, pero escaso, con potencial para ser usado en la fabricación de mermeladas y dulces. La madera es empleada en la fabricación de tajonas y mangos de herramientas.

Las frutas son utilizadas en forma Instituto de Nutrición fresca, refrescos, ensaladas, jaleas de Centro América y o mermeladas, sorbetes y postres, y Panamá - Secretaría diversos usos industriales sobre todo Ejecutiva del Consejo a nivel farmacéutico. Son ricas en Agropecuario Vitamina C, fuente de fibra, potasio, Centroamericano, 2017 magnesio y calcio. 


\begin{tabular}{|c|c|c|c|c|}
\hline Rutaceae & $\begin{array}{l}\text { Citrus } x \text { paradisi } \\
\text { Macfadyen }\end{array}$ & Toronja & $\begin{array}{l}\text { Tiene compuestos poli fenólicos y flavonoides } \\
\text { con potencial antioxidante como barredor } \\
\text { de radicales libres, por sus actividades } \\
\text { antibacterianas, antifúngicas, antivirales, } \\
\text { antiinflamatorias e inmunomoduladoras. } \\
\text { El aceite esencial de cáscara de la toronja } \\
\text { presenta actividad antimicrobiana, } \\
\text { particularmente contra los hongos. }\end{array}$ & $\begin{array}{l}\text { de la Rosa- } \\
\text { Hernández et } \\
\text { al., } 2016\end{array}$ \\
\hline Rutaceae & $\begin{array}{l}\text { Citrus reticulata } \\
\text { Blanco }\end{array}$ & Mandarina & $\begin{array}{l}\text { La fruta se consume fresca o para preparar } \\
\text { jugos, néctares y concentrados. Sus } \\
\text { principales nutrientes son la Vitamina } \mathrm{C} \text { y el } \\
\text { Potasio; se recomienda en la medicina natural } \\
\text { para prevenir infecciones, enfermedades del } \\
\text { corazón, ciertos tipos de cáncer, problemas } \\
\text { cerebro vasculares e hipertensión arterial. El } \\
\text { té de su cáscara alivia los dolores musculares } \\
\text { y de huesos. }\end{array}$ & $\begin{array}{l}\text { Autoridad } \\
\text { del Canal de } \\
\text { Panamá, } 2009\end{array}$ \\
\hline Rutaceae & $\begin{array}{l}\text { Citrus } x \text { aurantifolia } \\
\text { (Christm.) Swingle }\end{array}$ & $\begin{array}{l}\text { Limón } \\
\text { Criollo }\end{array}$ & $\begin{array}{l}\text { Es utilizado para preparar bebidas naturales } \\
\text { y para aderezar diversas comidas. Tiene un } \\
\text { alto contenido de Vitamina C y es usado } \\
\text { en farmacopea y en la industria cosmética. } \\
\text { Además del aceite esencial utilizado como } \\
\text { agente de sabor, perfumería, jabones de } \\
\text { tocador y cosméticos, es también utilizado en } \\
\text { bebidas carbonatadas, así como en pastelería, } \\
\text { elaboración de galletas y licores. }\end{array}$ & $\begin{array}{l}\text { Autoridad } \\
\text { del Canal de } \\
\text { Panamá, } 2009\end{array}$ \\
\hline Rutaceae & Citrus limetta Risso & Lima & $\begin{array}{l}\text { Los jugos son destinados a la extracción de } \\
\text { zumos y variedades de subproductos con } \\
\text { el fin de reducir el riesgo a enfermedades } \\
\text { crónicas especialmente del cáncer por sus } \\
\text { propiedades antioxidantes. El jugo es rico en } \\
\text { Vitamina C. }\end{array}$ & $\begin{array}{l}\text { Domínguez \& } \\
\text { Ordoñez, } 2013\end{array}$ \\
\hline Sapindaceae & $\begin{array}{l}\text { Melicoccus bijugatus } \\
\text { Jacq. }\end{array}$ & Mamón & $\begin{array}{l}\text { Su fruto se consume fresco, conservas o frutas } \\
\text { enlatadas. La pulpa puede ser utilizada para } \\
\text { preparar cerveza o aguardiente. La bebida } \\
\text { que se prepara de la cocción de la hoja con } \\
\text { sal se usa para prevenir desórdenes nerviosos } \\
\text { y fiebres. }\end{array}$ & $\begin{array}{l}\text { Autoridad } \\
\text { del Canal de } \\
\text { Panamá, } 2009\end{array}$ \\
\hline Sapindaceae & $\begin{array}{l}\text { Nephelium } \\
\text { lappaceum } \mathrm{L} .\end{array}$ & $\begin{array}{l}\text { Mamón } \\
\text { Chino }\end{array}$ & $\begin{array}{l}\text { De frutos de color amarillo o rojo en el } \\
\text { exterior, por dentro la parte comestible que } \\
\text { rodea la semilla es de un tejido suculento y } \\
\text { translúcido que contiene un jugo azucarado } \\
\text { que contiene compuestos bioactivos como } \\
\text { la Vitamina C y fenoles totales, además de } \\
\text { que la semilla contiene un alto porcentaje de } \\
\text { aceite. }\end{array}$ & $\begin{array}{l}\text { León, 2000; } \\
\text { Avendaño- } \\
\text { Arrazate et al., } \\
2018 .\end{array}$ \\
\hline Sapindaceae & $\begin{array}{l}\text { Dimocarpus longan } \\
\text { Lour. }\end{array}$ & Longán & $\begin{array}{l}\text { El fruto se consume fresco, en jugo o bebidas } \\
\text { preparadas. Es usado tradicionalmente como } \\
\text { medicina botánica para dolores de estómago, } \\
\text { insomnia y como antídoto de venenos. El } \\
\text { fruto contiene Fósforo, Hierro, Vitamina } \\
\text { A, Vitamina B1, Vitamina B2, Niacina y } \\
\text { Vitamina C. }\end{array}$ & $\begin{array}{l}\text { Mishra et al., } \\
2015\end{array}$ \\
\hline Sapotaceae & $\begin{array}{l}\text { Chrysophyllum } \\
\text { cainito L. }\end{array}$ & Caimito & $\begin{array}{l}\text { Su fruto tiene propiedades para aliviar la } \\
\text { inflamación de la laringitis y la neumonía, así } \\
\text { como el tratamiento de la diabetes, la angina } \\
\text { de pecho y afecciones intestinales, además } \\
\text { de otras propiedades medicinales. Su madera } \\
\text { es de excelente calidad y se utiliza para } \\
\text { construcciones pesadas, carpintería, muebles } \\
\text { de lujo, entre otros fines. }\end{array}$ & Chizmar, 2009 \\
\hline Solanaceae & $\begin{array}{l}\text { Solanum quitoense } \\
\text { Lam. }\end{array}$ & Naranjilla & $\begin{array}{l}\text { Los frutos sirven para preparar jugos y } \\
\text { refrescos, a los que da un sabor acídulo muy } \\
\text { agradable y un aroma especial. }\end{array}$ & León, 2000 \\
\hline
\end{tabular}


Respecto a las especies maderables (Tabla 2), se encontró un total de 34 especies, distribuidas en 20 familias, dentro de las cuales la mayor cantidad de especies pertenecen a las familias Fabaceae (con 29,41\% [10 especies]), Malvaceae (con 8,82\% [3 especies]), Anacardiaceae (con
7,58\% [5 especies]) y Arecaceae (con 7,58\% [5 especies]); incluyendo especies maderables y ornamentales con beneficios para la nutrición y salud (medicinales) humana y animal. Las propiedades medicinales requieren aún ser estudiadas y valoradas.

\section{Tabla 2}

Lista de especies maderables de la Finca FZ

\begin{tabular}{|c|c|c|c|c|c|}
\hline Familia & $\begin{array}{l}\text { Nombre } \\
\text { Científico }\end{array}$ & $\begin{array}{l}\text { Nombre } \\
\text { Común }\end{array}$ & Usos maderables & $\begin{array}{l}\text { Beneficios } \\
\text { adicionales }\end{array}$ & $\begin{array}{l}\text { Referencia } \\
\text { literaria }\end{array}$ \\
\hline Anacardiaceae & $\begin{array}{l}\text { Anacardium } \\
\text { excelsum } \\
\text { (Bert. \& Balb.) } \\
\text { Skeels }\end{array}$ & $\begin{array}{l}\text { Espavé } \\
\text { Javillo }\end{array}$ & $\begin{array}{l}\text { Su madera es utilizada } \\
\text { para la construcción, } \\
\text { remos, botes y muebles. }\end{array}$ & $\begin{array}{l}\text { Las semillas tostadas al } \\
\text { fuego son comestibles. }\end{array}$ & $\begin{array}{l}\text { Peláez et al., } \\
\text { 2016; Pérez } \\
\text { \& Condit, } \\
2021\end{array}$ \\
\hline Annonaceae & $\begin{array}{l}\text { Cananga } \\
\text { odorata (Lam.) } \\
\text { Hook. f. \& } \\
\text { Thomson }\end{array}$ & $\begin{array}{l}\text { Ylang } \\
\text { Ylang }\end{array}$ & $\begin{array}{l}\text { El uso de su madera es } \\
\text { para fines generales. }\end{array}$ & $\begin{array}{l}\text { El aceite se usa en } \\
\text { perfumes y como } \\
\text { planta ornamental. }\end{array}$ & $\begin{array}{l}\text { Pérez \& } \\
\text { Condit, } 2021\end{array}$ \\
\hline Araliaceae & $\begin{array}{l}\text { Dendropanax } \\
\text { arboreus (L.) } \\
\text { Decne. \& } \\
\text { Planch. }\end{array}$ & Jamaico & $\begin{array}{l}\text { Se utiliza su madera } \\
\text { para fabricar artesanías, } \\
\text { juguetes, esculpidos, } \\
\text { tallados, construcción } \\
\text { rural y construcciones } \\
\text { inferiores. }\end{array}$ & $\begin{array}{l}\text { La infusión del } \\
\text { cocimiento de las } \\
\text { hojas se emplea } \\
\text { como remedio para la } \\
\text { fiebre y para lavados } \\
\text { intestinales, además } \\
\text { como pulpa de papel. }\end{array}$ & $\begin{array}{l}\text { Vázquez- } \\
\text { Yanes et al., } \\
1999\end{array}$ \\
\hline Bignoniaceae & $\begin{array}{l}\text { Tabebuia rosea } \\
\text { (Bertol.) A. DC. }\end{array}$ & Roble & $\begin{array}{l}\text { Su madera es utilizada } \\
\text { para muebles finos, } \\
\text { pisos, gabinetes, } \\
\text { ebanistería, chapas } \\
\text { decorativas, artesanías, } \\
\text { ruedas de carretas, } \\
\text { cajas, embalajes, culatas } \\
\text { de armas de fuego y } \\
\text { botes. }\end{array}$ & $\begin{array}{l}\mathrm{La} \text { corteza y las } \\
\text { hojas se utilizan en la } \\
\text { medicina tradicional, } \\
\text { además de que es un } \\
\text { árbol ornamental. }\end{array}$ & $\begin{array}{l}\text { Peláez et al., } \\
\text { 2016; Pérez } \\
\text { \& Condit, } \\
2021\end{array}$ \\
\hline Bignoniaceae & $\begin{array}{l}\text { Tabebuia } \\
\text { guayacan } \\
\text { (Seem.) Hemsl. }\end{array}$ & Guayacán & $\begin{array}{l}\text { Madera utilizada para } \\
\text { construcciones navales, } \\
\text { puentes y durmientes de } \\
\text { ferrocarril. }\end{array}$ & Es un árbol ornamental. & $\begin{array}{l}\text { Peláez et al., } \\
2016\end{array}$ \\
\hline Boraginaceae & $\begin{array}{l}\text { Cordia alliodora } \\
\text { (Ruiz \& Pav.) } \\
\text { Oken. }\end{array}$ & Laurel & $\begin{array}{l}\text { Su madera se utiliza } \\
\text { para la construcción, } \\
\text { fábrica de muebles, } \\
\text { instrumentos musicales, } \\
\text { postes, vigas, construir } \\
\text { paneles de pared y de } \\
\text { techo. }\end{array}$ & $\begin{array}{l}\text { Las hojas y tallos } \\
\text { tiernos se usan en } \\
\text { forma de cataplasmas } \\
\text { como desinfectante } \\
\text { en la cicatrización de } \\
\text { heridas y úlceras. }\end{array}$ & $\begin{array}{l}\text { Takano et al., } \\
\text { 2000; Pérez } \\
\text { \& Condit, } \\
2021\end{array}$ \\
\hline Burseraceae & $\begin{array}{l}\text { Bursera } \\
\text { simaruba (L.) } \\
\text { Sarg. }\end{array}$ & $\begin{array}{l}\text { Cholo } \\
\text { Pelao, } \\
\text { Almácigo, } \\
\text { Carate, } \\
\text { indio en } \\
\text { cuera }\end{array}$ & $\begin{array}{l}\text { Su madera es empleada } \\
\text { para fines generales. }\end{array}$ & $\begin{array}{l}\text { Como postes de } \\
\text { cercas vivas. La savia } \\
\text { resinosa del tronco se } \\
\text { utiliza como sustituto } \\
\text { de la goma arábiga } \\
\text { y tiene propiedades } \\
\text { medicinales. }\end{array}$ & $\begin{array}{l}\text { Pérez \& } \\
\text { Condit, } 2021\end{array}$ \\
\hline
\end{tabular}




\section{Calophyllaceae Calophyllum brasiliense \\ Cambess.}

\section{Combretaceae Terminalia amazonica (J.F. Gmel.) Excell}

Euphorbiaceae L.
Palo María La madera se utiliza para muebles, carpintería, armaduras de embarcaciones, construcción en general, traviesas, contrachapado, paredes y pisos.

Amarillo

La madera es utilizada en barcos, muebles, mangos, herramientas y puentes.

La madera se utiliza para usos generales.

$\begin{array}{clcl}\text { Fabaceae } & \begin{array}{l}\text { Myroxylon } \\ \text { balsamun (L.) }\end{array} & \text { Bálsamo } & \begin{array}{l}\text { La madera es utilizada } \\ \text { en la fabricación de } \\ \text { Harms }\end{array} \\ & \text { guitarras, carpintería y } \\ \text { la ebanistería. }\end{array}$

Fabaceae

Fabaceae

Fabaceae

Fabaceae

\section{Gliricidia sepium (Jacq.) \\ Kunth ex Walp.}

Balo

Andira inermis (W.Wright) Kunth ex DC.

Harino, de río

Cassia fistula $\mathrm{L}$

Hymenaea
courbaril L.
Almendro

Coquillo la ebanistería.

Su madera se utiliza para usos generales y para leña.

Su madera es empleada en construcciones navales, durmientes de ferrocarril, mangos de herramientas, postes de cercas y en la fabricación de muebles.

La madera de la planta se puede utilizar en ebanistería, construcciones y postes. También se utiliza para leña y carbón.

Algarrobo Su madera es utilizada en la construcción pesada, postes, columnas, vigas, ejes de carretas, ebanistería y carpintería en general.
El látex que mana del Vázqueztronco (bálsamo de Yanes et al., María), la corteza y 1999; Takano el aceite de la semilla et al., 2000. tiene fines medicinales. El fruto se utiliza como forraje de ganado

La corteza contiene taninos y se utiliza para curtir y teñir pieles. Se puede utilizar para papel, además se puede utilizar como ornamental.

Autoridad del Canal de Panamá, 2007; Pérez \& Condit, 2021

Las hojas se emplean Pérez \& para tratar las Condit, 2021 inflamaciones de las erisipelas. La savia se usa como desinfectante para cicatrizar heridas y curar granos y llagas de la boca. Se utiliza para cercas vivas.

La resina que sale de Pérez \& las heridas al tronco tiene propiedades medicinales y se utiliza como ungüento, jarabe para la tos y en la cicatrización de heridas.

Es utilizada para cercas Sabillón \& vivas y como árbol de sombra. Como abono verde y la producción de forraje.

Puede ser empleada Pérez \&

como planta Condit, 2021 ornamental.

Bustamante, 1996

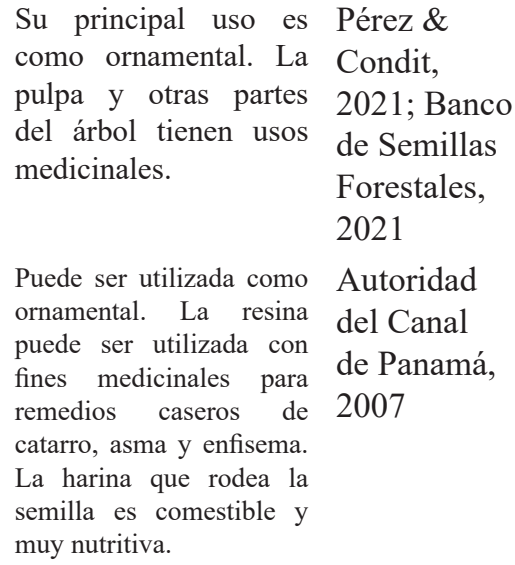

pulpa y otras partes 2021; Banco de Semillas Forestales, 2021

Autoridad del Canal de Panamá, 2007 


\begin{tabular}{|c|c|c|c|c|c|}
\hline Fabaceae & $\begin{array}{l}\text { Dalbergia retusa } \\
\text { Hemsl. }\end{array}$ & Cocobolo & $\begin{array}{l}\text { Madera posee una } \\
\text { sustancia aceitosa de } \\
\text { acción preservante y } \\
\text { hermoso pulimento útil } \\
\text { para elaborar artesanías, } \\
\text { confeccionar muebles } \\
\text { y artefactos deportivos, } \\
\text { piezas de ajedrez, } \\
\text { mangos de herramientas, } \\
\text { mangos de paraguas, } \\
\text { ruedas de timón, cajitas } \\
\text { para joyas, botones y } \\
\text { cuentas de rosarios. }\end{array}$ & Ornamental. & $\begin{array}{l}\text { Autoridad } \\
\text { del Canal } \\
\text { de Panamá, } \\
2008\end{array}$ \\
\hline Fabaceae & $\begin{array}{l}\text { Platymiscium } \\
\text { pinnatum (Jacq.) } \\
\text { Dugand }\end{array}$ & Quirá & $\begin{array}{l}\text { Posee una madera muy } \\
\text { fina que se utiliza en la } \\
\text { fabricación de muebles, } \\
\text { pisos, artesanía e } \\
\text { instrumentos musicales } \\
\text { por su facilidad para } \\
\text { trabajar. }\end{array}$ & Ornamental. & $\begin{array}{l}\text { Takano et } \\
\text { al., } 2000\end{array}$ \\
\hline Fabaceae & $\begin{array}{l}\text { Peltogyne } \\
\text { purpurea } \text { Pittier }\end{array}$ & Nazareno & $\begin{array}{l}\text { Su madera se utiliza en la } \\
\text { ebanistería, construcción } \\
\text { pesada, escultura, } \\
\text { arquitectura naval, para } \\
\text { hacer muebles, pisos, } \\
\text { mangos de herramientas, } \\
\text { artesanías, etc. }\end{array}$ & Ornamental. & $\begin{array}{l}\text { Takano et } \\
\text { al., } 2000\end{array}$ \\
\hline $\begin{array}{l}\text { Fabaceae } \\
\text { Papilionoideae }\end{array}$ & $\begin{array}{l}\text { Dipteryx } \\
\text { oleifera } \text { Benth. }\end{array}$ & $\begin{array}{l}\text { Almendro, } \\
\text { Almendro } \\
\text { de } \\
\text { Montaña }\end{array}$ & $\begin{array}{l}\text { Madera utilizada } \\
\text { en artesanías, } \\
\text { construcciones pesadas } \\
\text { para puentes y en la } \\
\text { construcción marina. }\end{array}$ & $\begin{array}{l}\text { Es hábitat de una } \\
\text { gran diversidad de } \\
\text { especies de la fauna } \\
\text { silvestre. }\end{array}$ & $\begin{array}{l}\text { Autoridad } \\
\text { del Canal } \\
\text { de Panamá, } \\
2008\end{array}$ \\
\hline $\begin{array}{l}\text { Fabaceae } \\
\text { Papilionoideae }\end{array}$ & $\begin{array}{l}\text { Diphysa } \\
\text { americana } \\
\text { (Mill.) M. Sousa }\end{array}$ & $\begin{array}{l}\text { Macano } \\
\text { Cacique }\end{array}$ & $\begin{array}{l}\text { Su madera puede } \\
\text { ser utilizada en } \\
\text { construcciones rurales, } \\
\text { horcones, postes de } \\
\text { cercas, mangos de } \\
\text { herramientas, carpintería } \\
\text { y ebanistería. }\end{array}$ & $\begin{array}{l}\text { Es plantada como } \\
\text { ornamental en } \\
\text { parques y avenidas. }\end{array}$ & $\begin{array}{l}\text { Pérez \& } \\
\text { Condit, } \\
2021\end{array}$ \\
\hline Lauraceae & $\begin{array}{l}\text { Cinamomum } \\
\text { triplinerve } \\
\text { (Ruiz \& Pav.) } \\
\text { Korsterm. }\end{array}$ & Sigua & $\begin{array}{l}\text { La madera es empleada } \\
\text { en la construcción } \\
\text { de puentes y pisos } \\
\text { industriales. }\end{array}$ & Ornamental. & $\begin{array}{l}\text { Pérez \& } \\
\text { Condit, } \\
2021\end{array}$ \\
\hline Malvaceae & $\begin{array}{l}\text { Cavanillesia } \\
\text { plantanifolia } \\
\text { (Bonpl.) Kunth }\end{array}$ & $\begin{array}{l}\text { Cuipo - } \\
\text { Bongo }\end{array}$ & $\begin{array}{l}\text { La madera sirve para la } \\
\text { fabricación de pulpa de } \\
\text { papel, construir canoas, } \\
\text { bateas para lavar ropa y } \\
\text { tazas para otros usos. }\end{array}$ & $\begin{array}{l}\text { El exudado del árbol } \\
\text { tiene diversos usos } \\
\text { medicinales. La madera } \\
\text { cuando se descompone } \\
\text { puede emplearse como } \\
\text { abono. }\end{array}$ & $\begin{array}{l}\text { Sabillón \& } \\
\text { Bustamante, } \\
\text { 1996; } \\
\text { Betancourt, } \\
2000\end{array}$ \\
\hline Malvaceae & $\begin{array}{l}\text { Sterculia apetala } \\
\text { (Jacq.) Karst }\end{array}$ & Panamá & $\begin{array}{l}\text { La madera se utiliza en } \\
\text { fabricación de muebles, } \\
\text { construcciones rurales, } \\
\text { postes de cerca, fabricación } \\
\text { de canoas, formaletas, } \\
\text { cajas de empaque, palillos } \\
\text { de fósforos, espátulas de } \\
\text { uso médico, tableros de } \\
\text { partículas y contrachapado. }\end{array}$ & $\begin{array}{l}\text { las semillas son } \\
\text { comestibles crudas, } \\
\text { cocidas o tostadas; las } \\
\text { flores, corteza, hojas y } \\
\text { semillas se utilizan para } \\
\text { remedios caseros, para la } \\
\text { previsión de afecciones } \\
\text { pulmonares respiratorias, } \\
\text { reumatismo, insomnio y } \\
\text { como estimulante. }\end{array}$ & $\begin{array}{l}\text { Autoridad } \\
\text { del Canal } \\
\text { de Panamá, } \\
2008\end{array}$ \\
\hline
\end{tabular}




\begin{tabular}{|c|c|c|c|c|c|}
\hline Malvaceae & $\begin{array}{l}\text { Azadirachta } \\
\text { indica A. Juss. }\end{array}$ & Nim & $\begin{array}{l}\text { La madera se utiliza de } \\
\text { manera general y como } \\
\text { leña. }\end{array}$ & $\begin{array}{l}\text { Planta ornamental y tiene } \\
\text { diversas propiedades } \\
\text { medicinales además que } \\
\text { contiene compuestos que } \\
\text { se extraen de esta planta } \\
\text { que tienen actividad } \\
\text { insecticida. }\end{array}$ & $\begin{array}{l}\text { Sabillón \& } \\
\text { Bustamante, } \\
\text { 1996; Pérez } \\
\text { \& Condit, } \\
2021\end{array}$ \\
\hline Meliaceae & $\begin{array}{l}\text { Swietenia } \\
\text { macrophylla } \\
\text { King }\end{array}$ & $\begin{array}{l}\text { Caoba } \\
\text { Nacional }\end{array}$ & $\begin{array}{l}\text { De madera muy fuerte y } \\
\text { preciosa utilizada para } \\
\text { muebles, gabinetes, } \\
\text { instrumentos musicales y } \\
\text { construcción en general. }\end{array}$ & $\begin{array}{l}\text { La corteza y las } \\
\text { semillas tienen uso } \\
\text { medicinal contra la } \\
\text { fiebre y la diarrea. }\end{array}$ & $\begin{array}{l}\text { Peláez et al., } \\
\text { 2016; Pérez } \\
\text { \& Condit, } \\
2021\end{array}$ \\
\hline Meliaceae & $\begin{array}{l}\text { Cedrela odorata } \\
\text { L. }\end{array}$ & $\begin{array}{l}\text { Cedro } \\
\text { Amargo }\end{array}$ & $\begin{array}{l}\text { Se usa para la fabricación } \\
\text { de muebles finos, } \\
\text { carpintería, gabinetes, } \\
\text { ebanistería, tablilla, } \\
\text { instrumentos musicales, } \\
\text { lápices, esculturas, chapa } \\
\text { y madera contrachapada } \\
\text { (plywood corriente y } \\
\text { decorativo). }\end{array}$ & $\begin{array}{l}\text { Las raíces y la corteza } \\
\text { del tronco se utilizan } \\
\text { en la medicina } \\
\text { tradicional, para curar } \\
\text { fiebres, diarreas, } \\
\text { dolores de estómago y } \\
\text { parásitos intestinales. }\end{array}$ & $\begin{array}{l}\text { Takano et } \\
\text { al., 2000; } \\
\text { Pérez \& } \\
\text { Condit, } \\
2021\end{array}$ \\
\hline Myrtaceae & $\begin{array}{l}\text { Eucalyptus } \\
\text { citriodora Hook. }\end{array}$ & Eucalipto & $\begin{array}{l}\text { La madera en aserríos } \\
\text { para la construcción en } \\
\text { general, postes, mangos } \\
\text { de herramientas y } \\
\text { traviesas de ferrocarril. } \\
\text { También es utilizada } \\
\text { como leña y carbón. }\end{array}$ & $\begin{array}{l}\text { El aceite conocido } \\
\text { como citronela que se } \\
\text { utiliza en perfumería. }\end{array}$ & $\begin{array}{l}\text { Takano et } \\
\text { al., 2000; } \\
\text { Banco de } \\
\text { Semillas } \\
\text { Forestales, } \\
2021\end{array}$ \\
\hline Pinaceae & $\begin{array}{l}\text { Pinus caribaea } \\
\text { Morelet }\end{array}$ & Pino & $\begin{array}{l}\text { Su madera es utilizada } \\
\text { en la construcción, } \\
\text { fabricación } \\
\text { muebles, artesanías, } \\
\text { contrachapado, pisos, } \\
\text { postes de tendido } \\
\text { eléctrico, para leña y } \\
\text { carbón. }\end{array}$ & $\begin{array}{l}\text { Se utiliza para extraer } \\
\text { resinas y pulpa para } \\
\text { papel. }\end{array}$ & $\begin{array}{l}\text { Takano et } \\
\text { al., 2000; } \\
\text { Pérez \& } \\
\text { Condit, } \\
2021\end{array}$ \\
\hline Rubiaceae & $\begin{array}{l}\text { Genipa } \\
\text { americana } \mathrm{L} .\end{array}$ & Jagua & $\begin{array}{l}\text { Su madera es empleada } \\
\text { en la fabricación de } \\
\text { carrocerías, mangos } \\
\text { de herramientas y en } \\
\text { carpintería. }\end{array}$ & $\begin{array}{l}\text { La pulpa que rodea } \\
\text { las semillas del fruto } \\
\text { maduro es comestible } \\
\text { con un sabor dulce y } \\
\text { algo rancio. }\end{array}$ & $\begin{array}{l}\text { Pérez \& } \\
\text { Condit, } \\
2021\end{array}$ \\
\hline Salicaceae & $\begin{array}{l}\text { Salix } \\
\text { humboldtiana } \\
\text { Willd. }\end{array}$ & Sauce & $\begin{array}{l}\text { Para la construcción rural, } \\
\text { fabricación de barriles, } \\
\text { aros, postes, cajones y } \\
\text { ebanisterías. Las ramas } \\
\text { delgadas y flexibles se } \\
\text { utilizan para hacer canastos } \\
\text { y muebles de mimbre; se } \\
\text { utilizan también para leña y } \\
\text { carbón. }\end{array}$ & $\begin{array}{l}\text { Se utiliza como forraje } \\
\text { crudo. Contiene } \\
\text { salicilatos que son } \\
\text { utilizados como bases } \\
\text { para la preparación de } \\
\text { aspirinas y disolventes } \\
\text { del ácido úrico. La } \\
\text { corteza contiene taninos } \\
\text { y un alcaloide llamado } \\
\text { salicina, sucedáneo de la } \\
\text { quinina. }\end{array}$ & $\begin{array}{l}\text { Vázquez- } \\
\text { Yanes et al., } \\
1999\end{array}$ \\
\hline Sapotaceae & $\begin{array}{l}\text { Manilkara } \\
\text { zapota }(\mathrm{DC}) \\
\text { Chov. }\end{array}$ & Níspero & $\begin{array}{l}\text { Su madera se utiliza en } \\
\text { la construcción, postes y } \\
\text { ebanistería. }\end{array}$ & $\begin{array}{l}\text { La savia lechosa se } \\
\text { utilizó en el pasado } \\
\text { para la elaboración } \\
\text { del chicle o goma de } \\
\text { mascar. La pulpa de } \\
\text { los frutos maduros es } \\
\text { comestible. }\end{array}$ & $\begin{array}{l}\text { Takano et } \\
\text { al., 2000; } \\
\text { Pérez \& } \\
\text { Condit, } \\
2021\end{array}$ \\
\hline
\end{tabular}




\begin{tabular}{|c|c|c|c|c|c|}
\hline Sterculiaceae & $\begin{array}{l}\text { Guazuma } \\
\text { ulmifolia Lam. }\end{array}$ & Guácimo & $\begin{array}{l}\text { Su madera es empleada } \\
\text { en construcciones } \\
\text { internas, postes de cercas } \\
\text { y leña. }\end{array}$ & $\begin{array}{l}\text { Sirven también como } \\
\text { forraje para ganado. } \\
\text { La corteza, hojas, } \\
\text { flores y frutos tienen } \\
\text { uso medicinal contra } \\
\text { la fiebre, vómito, } \\
\text { gastritis, diabetes y las } \\
\text { erupciones epiteliales. }\end{array}$ & $\begin{array}{l}\text { Pérez \& } \\
\text { Condit, } \\
2021\end{array}$ \\
\hline Tiliaceae & $\begin{array}{l}\text { Luehea speciosa } \\
\text { Wild. }\end{array}$ & $\begin{array}{l}\text { Guácimo } \\
\text { Tortugo }\end{array}$ & $\begin{array}{l}\text { Su madera es empleada } \\
\text { en la elaboración de } \\
\text { cajones, tableros, } \\
\text { aglomerados y leña. }\end{array}$ & $\begin{array}{l}\text { La fibra de la corteza } \\
\text { es fuerte y se usa como } \\
\text { cuerda para amarrar, } \\
\text { así como pulpa para } \\
\text { papel. }\end{array}$ & $\begin{array}{l}\text { Pérez \& } \\
\text { Condit, } \\
2021\end{array}$ \\
\hline Tiliaceae & $\begin{array}{l}\text { Apeiba } \\
\text { tibourbou Aubl. }\end{array}$ & $\begin{array}{l}\text { Cortezo, } \\
\text { Peine de } \\
\text { mono }\end{array}$ & $\begin{array}{l}\text { Su madera blanca y } \\
\text { fibrosa en multilaminados } \\
\text { y como material de } \\
\text { embalaje. }\end{array}$ & $\begin{array}{l}\text { Es utilizada en la } \\
\text { fabricación de papel. } \\
\text { Las semillas contienen } \\
\text { aceite empleado como } \\
\text { brillantina para el } \\
\text { cabello. Es materia } \\
\text { prima para textiles y } \\
\text { cuerdas para amarrar. } \\
\text { El aceite extraído de } \\
\text { las semillas se utiliza } \\
\text { en medicina popular } \\
\text { contra el reumatismo. }\end{array}$ & $\begin{array}{l}\text { Pérez \& } \\
\text { Condit, } \\
2021\end{array}$ \\
\hline
\end{tabular}

Losjardines botánicosincentivanlaconciencia de conservar bosques, inicialmente exaltando la importancia de una comunidad balanceada de bacterias y hongos que contribuyen con el ciclo de nutrientes y con el reciclaje de la materia; destacando también la captación de dióxido de carbono $\left(\mathrm{CO}_{2}\right)$. Los frutales y maderables, como parte de un bosque, pueden producir su alimento por fotosíntesis y proveer refugio a diversas especies de seres vivos (Wohlleben, 2016).

Diversas especies de árboles en asociación pueden contribuir con la fijación de nitrógeno dentro de programas de restauración ecológica mejorando las condiciones de los suelos (Banco de Semillas Forestales, 2021). Árboles maderables y frutales pueden ser utilizados para reforestar y proteger los cauces de los ríos (Pérez \& Condit, 2021).

Con un inventario de 65 especies frutales y 34 especies maderables, que pueden irse incrementando paulatinamente con la introducción de nuevas especies además de la integración de senderos ecológicos dentro de la Finca FZ; se fundamenta el papel que puede jugar la finca como jardín didáctico, escolar, demostrativo, agro botánico, etnobotánico, regional y nacional (Vovides \& Hernández, 2006). Pero para llegar a este fin se requiere recursos que permitan integrar nuevas infraestructuras, personal calificado, equipamiento, entre otros elementos para la constitución del jardín botánico (Vovides \& Hernández, 2006); para lo cual, gobiernos regionales, instituciones estatales y entes privados interesados en la responsabilidad social, podrían contribuir gradualmente para hacerlo realidad.

De esta manera, en el futuro Finca FZ puede aspirar a establecer patrones de servicios, programas, carácter y concepto de diseño similares, por ejemplo, a los del Jardín Botánico de Bogotá José Celestino Mutis, Jardín Botánico Nacional de Cuba y Jardín Botánico de Barcelona; que funcionan con diversas fuentes de financiamiento que van desde estatal, municipal, institucional y privado, para poder establecer las colecciones en campo y áreas educativas, así como los espacios para las actividades, con un carácter nacional y mundial (López \& Cabeza, 2006).

Por tanto, entre los elementos fundamentales para establecer el jardín botánico, estarán la documentación y datos de las especies (Luna, 
2006); un protocolo para la adquisición, ingreso y manejo de material vegetal (Lascurain et al., 2006).

Por tanto, tomando la experiencia de destacados jardines botánicos (Thompson, 1972; Vovides \& Hernández, 2006), sugieren que la Finca FZ deberá orientarse a mantener documentadas las colecciones de plantas vivas mediante un sistema de registro y ubicación dentro del jardín; disponer de material útil para la investigación en campos tales como la sistemática, farmacología, etnobotánica; mantener equipos de trabajo con científicos, técnicos y jardineros; desarrollar planes de propagación empleando medios tradicionales o cultivo de tejidos; mantener personal especializado en horticultura para encargarse de cultivar las plantas del jardín; mantener la comunicación con educadores para realizar planes de difusión, interpretación y contacto directo con el público general.

\section{Conclusiones}

Del presente estudio, se concluye que la Finca FZ, con 65 especies frutales y 34 maderables, tiene potencial para convertirse en un jardín botánico, con múltiples aplicaciones tanto en educación como en investigación, innovación y desarrollo social; con un enfoque hacia la sostenibilidad.

Sin embargo, requiere la inversión en infraestructura, el establecimiento de alianzas estratégicas con diversos actores de la sociedad, así como la integración y capacitación de personal competente, para que de manera participativa e integral se establezca como referente regional y nacional.

\section{Agradecimientos}

A la familia Fernández-Zurita, por su colaboración y optimismo hacia los proyectos de conciencia social y ambiental. Al Ing. Elvis Rodríguez, Director del Centro de Innovación Agropecuaria de Divisa, Instituto de Innovación Agropecuaria de Panamá, por el apoyo logístico brindado. Además, Randy Atencio agradece al Sistema Nacional de Investigación SNI SENACYT.

\section{Referencias}

Acurio, L., Zamora, A., Salazar, D., Pérez, L., \& Valencia, A. (2015). Propiedades físicas, químicas, térmicas y nutricionales de la badea (Passiflora quadrangularis). Agroindustrial Science, 5, 95-101. https://doi.org/10.17268/ agroind. science.2015.02.01

Autoridad del Canal de Panamá. (2007). Manual de Reforestación: especies maderables tradicionales / Autoridad del Canal de Panamá. Cuenca Hidrográfica de Panamá (Vol. 2). Editora Sibauste. https://www.jica.go.jp/project/ spanish/panama/2515031E0/data/pdf/1-51_01. pdf

Autoridad del Canal de Panamá. (2008). Manual de Reforestación: especies maderables no tradicionales / Autoridad del Canal de Panamá. Cuenca Hidrográfica de Panamá (Vol. 3). Editora Sibauste. https://wpeus2sat01. blob.core.windows.net/micanaldev/2018/ cuencahidrografica/manualdereforestacion 111 . pdf

Autoridad del Canal de Panamá. (2009). Manual de Reforestación: especies frutales / Autoridad del Canal de Panamá. Cuenca Hidrográfica de Panamá (Vol. 4). Editora Sibauste. https://wpeus2sat01.blob.core.windows. net/micanaldev/2018/cuencahidrografica/ manualdereforestacion $1 \mathrm{v} \cdot \mathrm{pdf}$

Autoridad Nacional del Ambiente. (2010). Cuarto Informe Nacional de Panamá Ante el Convenio sobre la Diversidad Biológica. ANAM-Panamá. https://www.cbd.int/doc/world/pa/pa-nr-04-es. pdf

Avendaño-Arrazate, C. H., Moreno-Pérez, E. del C., Martínez-Damián, M. T., Cruz-Álvarez, O., \& Vargas-Madríz, H. (2018). Postharvest quality and behavior of rambutan (Nephelium lappaceum L.) fruits due to the effects of agronomic practices. Revista Chapingo. Serie horticultura, 24(1), 13-26. https://doi. org/10.5154/r.rchsh.2016.08.025

Blasco, G., \& Gómez, F. (2014). Propiedades funcionales del plátano (Musa sp.). Revista Médica de la Universidad Veracruzana, 14(2), 22-26. http://www.soporte.uv.mx/rm/num anteriores/revmedica_vol14_num2/articulos/ propiedades.pdf

Betancourt, A. (2000). Árboles maderables exóticos. Playa, Cuba. Editorial Científico-Técnica.

Banco de Semillas Forestales. (2021). Semillas. CATIE (Centro Agronómico Tropical de Investigación y Enseñanza). http://bsf.catie. ac.cr/ 
Chizmar, C. (2009). Plantas comestibles de Centroamérica. Santo Domingo de Heredia, Costa Rica: Instituto Nacional de Biodiversidad, INBio. http://www.cich.org/publicaciones/03/ INBIO-2009-Plantas-Comestibles-de-CA.pdf

de la Rosa-Hernández, M., Wong-Paz, J., MuñizMárquez, D., Carrillo-Inungaray, M., \& Sánchez-González, J. (2016). Compuestos fenólicos bioactivos de la toronja (Citrus paradisi) y su importancia en la industria farmacéutica y alimentaria. Revista Mexicana de Ciencias Farmacéuticas, 47(2), 22-35. https:// www.redalyc.org/pdf/579/57956610003.pdf

Domínguez, E., \& Ordoñez, E. (2013). Evaluación de la actividad antioxidante, vitamina c de zumos cítricos de lima dulce (Citrus limetta), Limón Tahití (Citrus latifolia), Limón Rugoso (Citrus jambhiri Lush) y Mandarina Cleopatra (Citrus reshni) almacenados en refrigeración. Investigación y Amazonía, 3(1), 30-35. https:// revistas.unas.edu.pe/index.php/revia/article/ view/78

Forero, E. (1989). Los Jardines Botánicos y la Conservación de la Naturaleza. Acta Botánica Brasílica,3(2), 315-322.https://www.scielo.br/j/ abb/a/wxY5tyy4ZGR3sDKHrgRCCqJ/?lang=pt

Grijalva, A. (2006). Flora útil etnobotánica de Nicaragua. MARENA-Nicaragua. http://www.bio-nica.info/biblioteca/ GrijalvaFloraUtilNicaragua.pdf

Hossain, M., Islam, M., Akhatar, S., \& Numan, S. (2016). Nutritional value and medicinal uses of Monkey Jack fruit (Artocarpus lakoocha). International Research Journal of Biological Sciences, 5(1), 60-53. http://www.isca.in/IJBS/ Archive/v5/i1/9.ISCA-IRJBS-2015-143.pdf

Imbach, P., Robalino, J., Zamora, J., Brenes, C., Sandoval, C., Cifuentes-Jara, M., \& Labbate, G. (2016). Escenarios de deforestación futura de Panamá. PNUMA-Panamá. https://redd.unfccc. int/uploads/2234_47_escenario_deforestacion_ panama.pdf

Instituto de Nutrición de Centro América y Panamá - Secretaría Ejecutiva del Consejo Agropecuario Centroamericano. (2017). Los frutos de la identidad: El libro de las frutas de Centroamérica y República Dominicana. Guatemala (2. ${ }^{\text {a }}$ ed.). INCAP. http://bvssan. incap.int/local/D/DCE-190.pdf

Lascurain, M., Sánchez, O., Luna, V., \& Iglesias, C. (2006). Adquisición, ingreso y manejo de material vegetal en un jardín botánico. En M. Lascurain, O. Gómez, O. Sánchez \& C. Hernández (eds.), Jardines botánicos conceptos, operación y manejo (pp. 121-128). Asociación
Mexicana de Jardines Botánicos, A.C. http:// www.concyteq.edu.mx/amjb/repositorio/ documentos/publ_esp/1_Jardines_Botanicos_ Conceptos_Operacion_y_Manejo_2006.pdf

León, J. (2000). Botánica de los Cultivos Tropicales (3. ${ }^{\text {a }}$ ed.). Editorial Agroamérica, IICA. San José, Costa Rica.

López, R., \& Cabeza, A. (2006). Proceso de diseño para un jardín botánico. En M. Lascurain, O. Gómez, O. Sánchez \& C. Hernández (eds.), Jardines botánicos conceptos, operación y manejo (pp. 69-90). Asociación Mexicana de Jardines Botánicos, A.C. http://www. concyteq.edu.mx/amjb/repositorio/documentos/ publ_esp/1_Jardines_Botanicos_Conceptos_ Operacion_y_Manejo_2006.pdf

Luna, V. (2006). Documentación y manejo de información de las colecciones de plantas vivas. En M. Lascurain, O. Gómez, O. Sánchez \& C. Hernández (eds.), Jardines botánicos conceptos, operación y manejo (pp. 113-119). Asociación Mexicana de Jardines Botánicos, A.C. http:// www.concyteq.edu.mx/amjb/repositorio/ documentos/publ_esp/1_Jardines_Botanicos Conceptos_Operacion_y_Manejo_2006.pdf

Martínez, L., Franco, V., \& Balcázar, T. (2012). Plan de Acción en Educación Ambiental para Jardines Botánicos de México. Asociación Mexicana de Jardines Botánicas, A.C., México. https://www.concyteq.edu.mx/amjb/pdf/plan digital.pdf

Ministerio de Ambiente. (2021). Finca FZ: Un laboratorio forestal en Soná. https://www. miambiente.gob.pa/finca-fz-un-laboratorioforestal-sona/

Mishra, D., Chakraborty, B., Rymbai, H., Deshkmukh, N., Jha, A., War, G., Paul D., Patel, R., Mishra, L., Roy, D., \& Lyngdoh, P. (2015). Longan (Dimocarpus longan Lour). En S.N. Gosh (ed.), Breeding of Underutilized Fruit Crops (pp. 255-279). https://www.cabdirect.org/cabdirect/ abstract/20173139122

Orellana, A. (2014). Catálogo de frutales nativos de Guatemala. Gobierno de Guatemala. Ministerio deAgricultura, Ganadería y Alimentación / ICTA (Instituto de Ciencia y Tecnología Agrícolas). https://www.icta.gob.gt/publicaciones/ Frutales\%20nativos/Catalogo $\% 20$ de $\% 20$ frutales $\% 20$ nativos $\% 20 \mathrm{de} \% 20$ Guatemala, $\% 20$ 2014.pdf

Organización de las Naciones Unidas para la Alimentación y la Agricultura. (2015). Análisis y diagnóstico de políticas agroambientales en Panamá. FAO. http://www.fao.org/3/i5211s/ i5211s.pdf 
Osorio-Espinoza, H., Leyva-Galán, Á., ToledoToledo, E., Marroquín-Agreda, F., \& GabrielHernández, M. (2019). La producción de rambután (Nephelium lappaceum L.) en Chiapas, México. Oportunidades para una producción agroecológica. Cultivos Tropicales, 40(1), a14-e14. https://www.redalyc.org/ jatsRepo/1932/193261173014/193261173014. pdf

Peláez, A., Ramírez, A., Villa, M., Szejner, M., Jaspe, S., Khem, T., \& Mitre, M. (2016). Árboles de Panamá. Aefe / Lycée Français.

https://chm.cbd.int/api/v2013/ d o c u ments / 05 B 386 D 2 - 5 B C D A 52 D - 6097 - F 853803 C C 619 / attachments $/ 205236 / \% \mathrm{C} 3 \% 81$ rboles $\% 20$ d e \% $20 \mathrm{Panama} \% 202016 \% 20$ - \% 20 aefe $\% 2 \mathrm{C} \% 20$ Licee $\% 20$ Francais.pdf

Pérez, R., \& Condit, R. (2021). Tree Atlas of Panama. http://ctfs.si.edu/PanamaAtlas/maintreeatlas. php

Pittí, A., Gaudin, Y., \& Hess, S. (2021). Caracterización de los espacios rurales en Panamá a partir de estadísticas nacionales: enfoque social, económico y demográfico. Comisión Económica para América Latina y el Caribe (CEPAL). https://repositorio.cepal.org/ bitstream/handle/11362/46797/1/S2100206 es.pdf

Ruiz, G. (2019). La erosión de los suelos en Panamá y sus impactos. El Tecnológico, 28(1), 1416. https://revistas.utp.ac.pa/index.php/eltecnologico/article/view/2116

Salazar-Díaz, R. (2015). Un modelo de finca integrada orientada a contribuir a la seguridad alimentaria de comunidades indígenas de Talamanca (Artículo informativo). Tecnología en Marcha, 28(2), 74-83. https://doi.org/10.18845/ tm.v28i2.2335

Saptarini, N., \& Herawati, I. (2017). Antioxidant Activity of Water Apple (Syzygium Aqueum) Fruit and Fragrant Mango (Mangifera odorata) Fruit. Asian Journal of Pharmaceutical and Clinical Research, 10(14), 54-56. https://doi. org/10.22159/ajpcr.2017.v10s2.19487
Takano, K., Hagiwara, T., Mariscal, E., Aguilar, E., Martínez, R., \& Carrión, J. (2000). Árboles de Interés Forestal en Panamá. ANAM (Autoridad Nacional del Ambiente) / JICA (Agencia de Cooperación Internacional del Japón). https://www.jica.go.jp/project/spanish/ panama/2515031E0/data/pdf/1-05_01.pdf

Thompson, P. (1972). The role of the botanic garden. Taxon, 21, 115-119. https://doi. org/10.2307/1219234

Vázquez-Yanes, C., Batis, A., Alcocer, M., Gual, M., \& Sánchez, C. (1999). Árboles y arbustos potencialmente valiosos para la restauración ecológica y la reforestación. Reporte técnico del proyecto J084. CONABIO - Instituto de Ecología, UNAM. http://www.conabio.gob. $\mathrm{mx} /$ institucion/proyectos/resultados/J084 Fichas $\% 20$ de $\% 20$ Especies.pdf

Vovides, A., \& Hernández, C. (2006). Concepto y tipos de jardines botánicos. En M. Lascurain, O. Gómez, O. Sánchez \& C. Hernández (eds.), Jardines botánicos conceptos, operación y manejo (pp. 15-19). Asociación Mexicana de Jardines Botánicos, A.C. http://www. concyteq.edu.mx/amjb/repositorio/documentos/ publ_esp/1_Jardines_Botanicos_Conceptos Operacion_y_Manejo_2006.pdf

Wohlleben, P. (2016). The Hidden Life of Trees: What They Feel, How They Communicate Discoveries from A Secret World (The Mysteries of Nature). Greystone Books.

Wyse, P., \& Sutherland, L. (2000). Agenda Internacional de Conservación de Jardines Botánicos. Organización Internacional para la Conservación en Jardines Botánicos.

https://www.concyteq.edu.mx/amjb/repositorio/ documentos/polit_doc/internacionales/Agenda_ Internacional_Conservacion_Jardines _ Botanicos.pdf 